\title{
Totalitarismo, democracia liberal e o "desafio de nossa época”
}

\author{
Totalitarianism, liberal democracy and the "challenge of our time"
}

DOI: $10.20873 /$ rpv6n2-03

\section{Rodrigo Ribeiro Alves Neto}

Orcid: 0000-0003-2834-5265

Email: rodrigo.alvesneto@gmail.com

\begin{abstract}
Resumo
0 artigo analisa o totalitarismo como uma resposta destrutiva ao que Arendt denomina "desafio de nossa época", explicitando o diagnóstico crítico da autora sobre a democracia liberal representar ou não uma "nova organização política" que propicie uma resposta construtiva ao desafio do mundo moderno.
\end{abstract}

\section{Palavras-chave}

Totalitarismo; Democracia; Política; Mundo Comum; Hannah Arendt.

\begin{abstract}
The article analyzes totalitarianism as a destructive response to what Arendt calls "the challenge of our time", explaining the author's critical diagnosis of whether liberal democracy represents or not an effective political organization as a constructive response to the challenge of the modern world.
\end{abstract}

\section{Keywords}

Totalitarianism; Democracy; Politics; Common World; Hannah Arendt

\section{Introdução}

No terceiro item da primeira seção de uma palestra proferida por Hannah Arendt em 28 de outubro de 1954, podemos ler: “0 totalitarismo é um fenômeno de decadência, mas em resposta ao desafio do mundo moderno. 0 mundo livre deve fazer o mesmo? Há um modo de desenhar uma nova organização política [polity]?” (2011a, p. 236). Em outros termos, se o 
totalitarismo é, em muitos aspectos, uma resposta precisa ao desafio do mundo moderno, "isso significa que somente o totalitarismo aceitou o desafio de nossa época? Que o mundo livre fracassou?" (2011a, p. 231).

Meu propósito nesta breve reflexão é contribuir para o esclarecimento desse diagnóstico crítico arendtiano e elaborar algumas de suas significações. Em primeiro lugar, procuro explicitar o sentido dessa compreensão do evento totalitário como "fenômeno de decadência". Em seguida, exponho de que modo Arendt pensou o totalitarismo como "resposta ao desafio do mundo moderno", evidenciando o que autora compreende como o "desafio de nossa época". Finalizo com uma análise da crítica arendtiana à democracia liberal e sua avaliação sobre a possibilidade dela representar ou não um "novo começo" para o desenho possível de uma "nova organização política” como resposta construtiva ao "desafio do mundo moderno".

\section{0 totalitarismo como "fenômeno de decadência"}

Em que sentido Arendt compreende o evento totalitário como um "fenômeno de decadência" em "resposta" ao desafio do mundo moderno? Seria um equívoco supormos que estamos diante de alguma atitude passadista que lamenta pelo "ocaso" ou "declínio" dos valores e princípios políticos tradicionais sobre os quais estavam fundadas nossa vida comum e cujo esmaecimento deu lugar ao advento do totalitarismo. Se assim fosse, só restaria a posição reacionária de restaurar a ordem e os fundamentos de outrora perdidos no presente. Contudo, um dos aspectos do termo "decadência" aqui aponta para a experiência de uma crise de natureza fundamentalmente política, uma vez que o recurso a alguma dimensão apolítica ou exterior à dignidade e grandeza próprias ao âmbito político apenas retardaria e agravaria a crise e a sua superação. Arendt se distancia tanto da concepção conservadora da crise como "declínio", buscando a restauração da ordem tradicional ou alguma autoridade perdida, quanto da concepção liberal que, em face da crise, reafirma o progresso e rejeita qualquer restrição à liberdade. Trata-se de compreender a "crise" de modo inteiramente positivo, como ressaltam Assis César e Duarte: 
Segundo a perspectiva arendtiana, a crise é um momento crucial, pois se trata de um momento decisivo que permite observar as deficiências daquilo que se encontra em crise, além de evidenciar o fracasso das tentativas de sua superação até o momento. Assim, muito mais grave do que a própria crise, é o fato de não a entendermos como momento propício para o pensamento crítico (2010, p. 834).

Os regimes totalitários são fenômenos de decadência porque romperam o fio de nossa tradição, usurpando a sua autoridade e desafiando as categorias usuais de nosso pensamento político. A novidade do totalitarismo iluminou o fim da tradição, evidenciando que haviam secado as fontes oficiais da narrativa histórica das quais deveriam advir os significados e a reconciliação compreensiva com os eventos do nosso tempo. A decadência que o totalitarismo exprime consiste na quebra da continuidade histórica, trazendo à tona uma crise radical da civilização ocidental, tornando explícito o colapso moral e espiritual da tradição, a perda do senso comum e a emergência das "correntes subterrâneas" da história ocidental (o antissemitismo, o racismo, o imperialismo, dentre outros elementos cristalizados no evento totalitário). Não se trata de um lamento pelo ocaso, pois a história sempre acontece a cada vez que um evento se manifesta grande o suficiente para romper o continuum do tempo e instaurar a irrupção de uma novidade no presente que projeta uma nova luz sobre o passado e o futuro.

A perda da tradição revela que não recebemos o passado por intermédio de uma mentalidade já constituída que herda, questiona, conta, seleciona e confere acabamento à história resultante do transcurso das ações dos homens no mundo. Por isso nossa presença no tempo se tornou insegura e desamparada, reivindicando uma nova relação entre pensamento, atualidade e tempo histórico, ou seja, uma rearticulação do modo como o presente se relaciona com o passado e o futuro. São nos tempos de crise, ruptura e grandes interferências no devir histórico que o pensamento é confrontado com dificuldades no exercício da atividade reflexiva, sendo reivindicado a tomar novas decisões, pois se vê desprovido de pressupostos e significações herdadas da tradição oficial. Como esclarece Arendt:

O desaparecimento dos pressupostos significa simplesmente que perdemos as respostas em que nos apoiávamos vulgarmente sem aceitar perceber que originariamente elas constituíam respostas a questões. Uma crise nos obriga a voltar às questões mesmas e exige de nós respostas, novas ou antigas, mas, de qualquer modo, julgamentos diretos. Uma crise só se torna desastrosa quando respondemos a ela com juízos pré-formados, isto é, com preconceitos. Uma atitude dessas não apenas aguça 
a crise como nos priva da experiência da realidade e da oportunidade por ela proporcionada à reflexão (2007, p. 223).

Nas circunstâncias em que a novidade do acontecimento no presente se desconecta da cadeia discursiva que orientou sucessivas gerações em sua compreensão do mundo, o homem se vê ameaçado pela ausência de sentido e pelo esquecimento, pois não consegue se reconciliar com a realidade atual, tornando-se incapaz de se sentir em casa no mundo, incapaz de contar a constituição de sua própria história através do fio condutor de significações tecido na cadeia discursiva do pensamento. Como "fenômeno de decadência", o totalitarismo aponta para essa experiência de fim e esgotamento, mas não no sentido hegeliano de resultado totalizante de um processo dialético transcendente e não no sentido conservador de Fukuyama, com seu diagnóstico de "fim da história" como ausência de contradições grandes o suficiente para causar uma ruptura no presente - como se, desprovidos de um horizonte de expectativa, não fôssemos mais capazes de imaginar um presente radicalmente diferente. Para Arendt, o totalitarismo foi uma “tempestade de areia" (2008, p. 268) no meio do deserto do mundo moderno, ou seja, uma tempestade que ameaçou "devastar o mundo que conhecemos - um mundo que, em toda parte, parece ter chegado ao fim - antes que um novo começo, surgindo desse fim, tenha tido tempo de se firmar" (ARENDT, 2004, p. 531). Esse "mundo que conhecemos" e que Arendt afirma "ter chegado ao fim" é o mundo ocidental-europeu sustentado pela trindade tradição, religião e autoridade. 0 totalitarismo é, em muitos aspectos, uma resposta precisa a esta perplexidade que iluminou o esgotamento das bases da convivência humana que marcaram a civilização europeia. Um dos aspectos do desafio do homem moderno consiste justamente em ter que viver em um mundo comum que já não depende de autoridade, religião e tradição para ser construído, conservado e compreendido. 0 enfraquecimento da tríade romana ao longo da era moderna foi iniciado com o Renascimento e com a moderna secularização, tendo se aprofundado com as filosofias do progresso histórico, que substituíram a teleologia escatológica cristã a partir dos séculos XVIII e XIX. O moderno declínio da autoridade está enraizado no enfraquecimento da noção de "fundação política", isto é, uma fonte de estabilidade e legitimidade amparada no cuidado para com a durabilidade do mundo comum, sua memória cultural, suas leis e instituições. Foi a perda da tríade romana que tornou possível repensarmos o quanto termos como 
"autoridade" e "poder" denominam fenômenos políticos distintos, ambos opostos à violência e repletos de confusões que obscurecem seus sentidos. Portanto, Arendt, ao invés de reafirmar “antigas verdades", parte da experiência do fim da tradição para pensar acontecimentos políticos e enfrentar impasses e problemas procedentes do mundo moderno, cuja maior dificuldade reside precisamente no fato de que a tradição sequer os previu.

\section{0 totalitarismo como resposta destrutiva ao "desafio do mundo moderno":}

O totalitarismo foi considerado por Arendt como uma "resposta destrutiva" (ARENDT, 2004, p. 12) para todos os impasses desafios políticos do mundo moderno. É decisiva essa compreensão do totalitarismo como "resposta", pois indica claramente o fato de tal regime não ter criado por si mesmo o "problema" ao qual pretendeu responder destrutivamente, ou seja, o problema emerge das próprias condições gerais do mundo não-totalitário que tornaram possível um regime apoiado na mobilização, aterrorização e doutrinação ideológica das massas. As condições prévias da dominação totalitária são condições gerais da época e, portanto, não devemos menosprezar a força destrutiva das "soluções totalitárias" (ARENDT, 2004, p. 511), visto que o totalitarismo evidenciou os impasses e os desafios políticos do mundo moderno. Por isso Arendt adverte que não devemos jamais ignorar a força destrutiva do evento totalitário, visto que sem ela: "poderíamos ter sido levados à ruína sem jamais saber o que estava nos acontecendo" (ARENDT, 2004, p. 13).

Mas o que estava nos acontecendo? Em que consiste esse desafio do mundo moderno? No texto "Ideologia e Terror", capítulo conclusivo inserido a partir da $2^{\text {a }}$ edição de Origens do totalitarismo, surgida em 1958, mesmo ano de publicação de A Condição Humana, a base sobre a qual se encontram assentados o terror (essência do governo totalitário) e a ideologia (a preparação de seus carrascos e vítimas) foi nomeada por Arendt com o termo loneliness (correntemente traduzido por solidão, mas também por desolação, abandono e desamparo). 0 desafio do mundo moderno, para o qual o totalitarismo apresentou uma "resposta destrutiva", consiste no desenraizamento e na superfluidade que assolam as massas modernas desde a Revolução Industrial, tornando-se decisivos com o imperialismo no fim do século XIX e a falência das 
instituições políticas tradicionais no século XX. "Não ter raízes significa não ter no mundo um lugar reconhecido e garantido pelos outros; ser supérfluo significa não pertencer ao mundo de forma alguma", afirma Arendt (2004, p. 528).

Desse modo, o totalitarismo representa uma "reposta destrutiva" ao desamparo das massas modernas porque seus meios totalitários de organização e dominação administraram justamente a sensação de superfluidade e o profundo desarraigamento dos homens em relação ao mundo comum e humano. E isso de tal modo que Arendt denominou o domínio total como “solidão organizada” (2004, p. 531), pois dispensa convicção, opinião, participação, juízo político, escolha, enfim, qualquer auxílio humano para a instituição e a preservação do mundo, qualquer traço de espontaneidade e imprevisibilidade, ou seja, tudo que possa distinguir um homem singular do outro. A dominação totalitária administrou condições em que desaparecem a relação do homem consigo mesmo no diálogo do pensamento, a relação do homem com o sentimento de realidade conferido ao mundo compartilhado pelo senso comum e a relação dos homens com o mundo enquanto obra humana e assunto comum de unicidades plurais que agem e falam. 0 desamparo é expressão da redução dos homens à mera reprodução repetitiva da sobrevida biológica, desenraizados do domínio político da ação tanto quanto da mundanidade do artifício humano, submetendo-se, assim, à mera recorrência circular e homogênea da natureza dentro da qual cada homem não passa da repetição continuamente reprodutível e previsível do mesmo modelo da espécie humana. 0 terror mantém juntos indivíduos solitários ou supérfluos e a ideologia os compele com a força coercitiva de sua logicidade. Os homens se tornam supérfluos e desenraizados do mundo comum quando se definem como seres naturais ou "repetições interminavelmente reproduzíveis do mesmo modelo, todos dotados da mesma natureza e essência, tão previsíveis quanto a natureza e essência de qualquer outra coisa”, diz Arendt (2001, p. 16).

Arendt se esforça por evidenciar o quanto a existência humana, quando excluída do serentre-os-outros em uma comunidade politicamente organizada, torna-se não meramente insegura e exposta à violência, mas, sobretudo, desprovida de sentido e liberdade, enfim, carente do espaço possível e necessário para um modo de vida autenticamente humano. A artificialidade, a durabilidade, a estabilidade, a intersubjetividade e a performatividade inerentes ao 
mundo comum e humano vinculam e distinguem os homens, instituindo um espaço inter-humano de relacionamentos, para além dos interesses privados e da unidade homogênea do gênero humano. Foi a "abstrata nudez de ser unicamente humano" e "a condição humana geral daqueles que foram expulsos de todas as comunidades políticas" (ARENDT, 2004, p. 334) que instigaram Arendt a pensar sobre a condição humana geral que torna possível e crucial a fundação de uma comunidade politicamente organizada.

Nesse sentido, ao contrário da visão liberal, Arendt não enxergou no totalitarismo a expressão máxima do excesso de política, a hiper-politização e subordinação extrema de todas as esferas da vida às exigências da política, o que destruiria a própria liberdade de isenção da política. Vendo nos regimes totalitários muito mais um projeto de destruição total do significado político-filosófico da liberdade ou do ser entre os outros, Arendt assumiu, na obra A Condição Humana e em diversos escritos posteriores, a tarefa político-filosófica de repensar o sentido e a dignidade do mundo como criação dos homens, do mundo humano erigido e mantido não apenas pela fabricação e pela durabilidade das coisas feitas pelos homens, mas, sobretudo, pela existência pública e ativa dos homens como singularidades plurais que, agindo e falando, instituem e conservam os laços, os dissensos e consensos, os compromissos e os interesses comuns no compartilhamento democrático do mundo que deve a sua existência exclusivamente a eles.

\section{A democracia liberal: uma resposta ao desafio do mundo moderno?}

A partir da obra A Condição Humana, Arendt ampliou suas análises críticas para uma confrontação com as formas hegemônicas de organização política vigentes nas democracias liberais realmente existentes, marcadas pela despolitização e pela atrofia dos espaços de liberdade e decisão conjunta dos cidadãos. Arendt buscou diagnosticar criticamente a base sobre a qual se encontram assentadas algumas de nossas mais importantes experiências políticas do presente, seja a novidade do "puro horror" da destruição totalitária do mundo comum, seja a hegemônica despolitização liberal e a aguda contração da esfera política nas atuais democracias formais de massa e mercado. Mesmo sem jamais apresentar os moldes para uma "nova organização política", com uma descrição positiva de modelos normativos e fechados, nem mesmo de 
origem greco-romana, Arendt avaliou de que modo, por um lado, os regimes totalitários foram a negação mais absoluta da liberdade, mas, por outro, a versão formal e representativa da democracia não seriam efetivamente um "novo começo". A democracia liberal também está estruturada no desenraizamento e na descartabilidade dos homens, obscurecendo o sentido político da liberdade e a liberdade como o sentido da política. A versão liberal e representativa da democracia moderna fortalece os preconceitos tradicionais sobre a política ao sediar a esfera do político no aparato do Estado e ao sustentar que a liberdade começa onde a política termina. A vida política seria um "mal necessário", pois quanto menos política, mais liberdade, o que intensifica a oposição entre política e liberdade e a identificação entre poder e violência.

Enxergando no totalitarismo a pretensão de subordinar todas as esferas da vida às exigências da política, destruindo a individualidade e as liberdades civis, sobretudo a liberdade de isenção da política, a democracia liberal aprofundou a sua convicção sobre a incompatibilidade entre política e liberdade. É neste sentido que a democracia liberal, representativa, de partidos burocratizados, para Arendt, não realiza as potencialidades da democracia radical,

transformando-se rapidamente em uma nova forma de elitismo político ou resvalando em um formalismo que reserva pouquíssimo espaço para a autêntica vida cívica. Como se esses obstáculos não fossem suficientes, ainda seria possível detectar na base do sistema democrático moderno alguns dos elementos que permitem compreender a ascensão dos regimes totalitários: o desinteresse pela coisa pública, a massificação do povo e a atomização do indivíduo (ADVERSE, 2018, p. 141).

A política passa, então, a ser pensada como garantia de segurança aos direitos dos indivíduos, com a função de resguardar as necessidades sociais e as liberdades apolíticas de pensamento, religião, expressão, atividade econômica e toda a esfera privada da vida, na qual os homens possam exercer atividades realizadas fora do lado público do mundo. Em suma, afastados da vida pública, os cidadãos são submetidos a uma estrutura representativa que promete ajustar duas dimensões dessa democracia liberal: o seu crescente individualismo e o exercício do poder por governos cuja finalidade é essencialmente econômica. A despolitização generalizada da sociedade reduz a democracia à mera defesa das liberdades individuais de produzir e consumir e à administração competente do progressivo desenvolvimento uniforme da esfera socioeconômica. A transformação da política em gestão tecnocrática da esfera sócio-econômica 
nutre nos cidadãos a crença de que o fator que rege nossos engajamentos ativos com o mundo comum é apenas a eterna necessidade imposta a nós pelos processos inflexíveis da vida biológica e que nós, portanto, dependemos uns dos outros apenas para garantirmos as tarefas necessárias à reprodução da esfera social e econômica. A reflexão arendtiana nos ensina que não será jamais suficiente lutarmos contra tudo que ameaça nossos direitos sociais e nossa felicidade privada se abdicarmos de lutarmos, sobretudo, contra o próprio modo como a socialização do labor e do consumo e a sobredeterminação econômica da política ameaçam hoje nossos direitos públicos, sobre os quais deveriam estar verdadeiramente fundados nosso direito a ter direitos e a nossa felicidade pública. A democracia liberal transforma a vida política em procedimento eleitoral para o gerenciamento governamental, ou seja, mero instrumento utilitário para salvaguardar a paz interna e a defesa das liberdades individuais, que é condição necessária, mas ainda insuficiente para a liberdade política. Separando liberdade e política e associando poder e violência, as bases liberais de nossa democracia de massa e mercado nos fez acreditar que a participação direta nas decisões coletivas submete o indivíduo e seus interesses privados à autoridade do todo, tornando-o não livre. A participação política direta foi substituída pela representação e a separação entre governantes e governados se aprofundou tanto que os poderes institucionais perderam credibilidade política e legitimidade, obscurecendo os meios que permitiriam a participação dos cidadãos nos assuntos públicos, deixando de ser manifestações e materializações do poder instituidor do mundo comum.

Por esta via, uma "nova organização política" que responda efetivamente ao desafio do mundo moderno precisa começar recusando a distinção entre liberdade e política e percebendo na fusão entre poder e violência os elementos proto-totalitários que hoje existem em todas as frágeis democracias realmente existentes. A tradicional vinculação entre poder, violência e "governo de ninguém" assim como a subordinação da política à proteção, otimização e controle da vida natural destroem o caráter revelador da ação e do discurso, transformando o "alguém" em "algo" intercambiável e substituível, destruindo a espontaneidade, a pluralidade e a capacidade dos homens de ocasionar algo novo no mundo que deve a sua existência a eles. Essa redução dos homens à condição de vida supérflua, torna o processo vital passível de otimização, mas também de controle, violência, exclusão e eliminação. As democracias liberais capturam o 
processo vital multiplicando suas potencialidades e utilizando-o como recurso, promovendo uma indiferenciação entre um modo de vida exclusivamente humano e o mero viver.

Não se trata, contudo, de simplesmente recusar a democracia parlamentar e eliminar o mecanismo representativo, mas encontrar alternativas para a representação capazes de redefini-la no sentido de preservar e estimular novas formas de participação ativa de cidadãos livres e organizados, capazes de agir em concerto e se fazerem ouvir. A preocupação arendtiana sempre foi desconstruir a compreensão liberal da democracia, o Estado de bem-estar social e o sistema representativo como modelos normativos inquestionáveis, recusando-os como um efetivo "outro começo" ou uma efetiva "nova organização política", pois eles obscurecem as dimensões da condição humana com as quais a esfera política está associada, ou seja, a ação, o discurso, a liberdade, a esfera pública e a pluralidade humana. A originalidade e a contemporaneidade do esforço arendtiano consistem, portanto, em evidenciar que somente no compartilhamento do mundo através de atos e palavras os homens podem ser autenticamente livres, isto é, nem movidos apenas por si próprios, com base em seus interesses privados, nem forçados pelas necessidades impostas pela manutenção da vida orgânica. A existência de um mundo comum como espaço intermediário da ação e da fala é a condição para que possamos estar livremente associados ao invés de justapostos, desprovidos de interesses mundanos, fundidos num só interesse ou fragmentados em interesses privados. 0 mundo comum precisa ser um espaço humano de liberdade e decisão conjunta dos cidadãos, ou seja, um espaço comum de participação plural na expressão, na discussão, na resistência, no dissenso e na ação coletiva pela qual o agonismo e a liberdade pudessem ser sempre revitalizados, ao menos por colocarem em tensão a representação política e a capacidade dos homens de agirem conjuntamente.

Arendt evidencia que um "outro começo" ou uma "nova organização política" que construa uma "resposta positiva" ao desafio do mundo moderno precisa compreender que a disseminação da violência no cenário político contemporâneo e a assimilação do poder aos meios da violência representam uma efetiva ameaça de destruição do sentido da política. Nesse sentido, a tarefa posta em causa nesse outro começo do pensamento político-filosófico reside na recusa da legitimação da violência como algo natural e do poder como naturalmente violento, pois fazer da violência a mais expressiva manifestação do poder reduz a política a mero meio para a 
obtenção e o exercício do poder. A vida democrática é uma forma de associação política baseada na igualdade e na liberdade porque multiplica os espaços da diferença em seu caráter incomensurável e irredutível ao consenso, entendido como a domesticação e neutralização da pluralidade humana. 0 mundo comum é habitado por uma pluralidade de seres singulares e não se torna comum a eles meramente porque a força limitada de cada faça todos depender do auxílio uns dos outros. Como diz Arendt: "Ou a liberdade política, em termos gerais, significa o direito de participar do governo ou não significa coisa alguma” (ARENDT, 2011b, p. 278). A liberdade está vinculada com a igualdade porque elas interditam a autonomia da individualidade e a atomização, uma vez que sem os outros homens que são meus iguais não posso ser politicamente livre. Arendt ressalta que "o homem que domina outros (...) é, de fato, mais feliz e invejável do que aqueles que ele domina, embora nem um pouco mais livre” (2008, p. 172). É neste sentido que as potencialidades da convivência ou simplesmente o "poder" democrático não é possuído como a força, nem exercido como a coação, pois é a perda do poder conjugado da ação o que primeiro destrói as organizações políticas. Não pode haver uma política aberta à novidade que se origina do livre agir coletivo senão por meio da capacidade de discordar, de dizer não e agir para interromper o processo contínuo de um determinado estado de coisas. É com base nesse diagnóstico crítico que Arendt conclui que a democracia liberal desertifica o mundo e divorcia a política da liberdade, tornando-se incapaz de neutralizar ou desativar inteiramente o totalitarismo, pois não configura uma efetiva "resposta construtiva" em face da "resposta destrutiva" do domínio total.

Se o empreendimento teórico de Arendt, como tantos pensadores da sua geração, teve como ponto de partida o evento "Auschwitz", o desafio de seu pensamento não foi apenas pensar "depois de Auschwitz", mas, sobretudo, pensar "o que resta de Auschwitz" entre nós e como enfrentar e superar as circunstâncias que tornaram possível o seu advento. 0 termo "Auschwitz" aqui já não nomeia apenas um campo de concentração e extermínio em massa, pois simboliza o extremo ao qual pode chegar a total destruição do sentido da política. Mantém-se terrivelmente atual o modo como o escritor húngaro Imre Kertész nos advertiu sobre a necessidade de não esquecermos que Auschwitz não acabou por ter sido Auschwitz, mas sim porque a "roda da fortuna da guerra mudou", visto que, desde Auschwitz, nada efetivamente aconteceu 
no mundo não-totalitário que pudéssemos interpretar como uma efetiva "refutação de Auschwitz". É nesse sentido que Arendt concluiu suas reflexões sobre o totalitarismo afirmando que essa forma inédita de mobilização, organização e dominação das massas permanecerá entre nós como tentação e advertência: "As soluções totalitárias podem muito bem sobreviver à queda dos regimes totalitários sob a forma de forte tentação que surgirá sempre que pareça impossível aliviar a miséria política, social e econômica de um modo digno do homem" (ARENDT, 2004, p. 511).

\section{Referências}

ARENDT, H. Entre o passado e o futuro. Trad. M. W. Barbosa de Almeida. 6.ed. São Paulo: Perspectiva, 2007. ARENDT, H. Origens do totalitarismo. Trad. R. Raposo. São Paulo: Companhia das Letras, 2004.

ARENDT, H. A Condição Humana. Trad. R. Raposo. Rio de Janeiro: Forense Universitária, 2001.

ARENDT, H. A Promessa da Política. Trad. P. Jorgensen. Rio de Janeiro: DIFEL, 2008.

ARENDT, H. Totalitarismo. Trad. A. Correia. Inquietude, v. 2, n. 2, ago/dez, 2011a.

ARENDT, H. Sobre a revolução. Trad. D. Bottmann. São Paulo: Companhia das Letras, 2011b.

ADVERSE, H. Arendt e a democracia representativa. Pensando - Revista de Filosofia. v. 9, n. 17, 2018.

ASSIS CÉSAR, M. R.; DUARTE, A. Hannah Arendt: pensar a crise da educação no mundo contemporâneo. Educação e Pesquisa. São Paulo, v. 36, n.3, p. 823-837, set./dez. 2010.

Recebido em: 05/12/2021

Aprovado em: 15/12/2021

\section{Rodrigo Ribeiro Alves Neto}

Bacharel e Licenciado (UFRJ) em Filosofia. Mestre (UERJ) e Doutor (PUC-Rio) em Filosofia. Professor Associado do Departamento de Filosofia da UNIRIO e Professor Colaborador do Programa de Pós-graduação em Filosofia da UFRN. Foi Professor Adjunto do Departamento de Filosofia da UFRN de 2009 a 2012. Líder do Grupo de Pesquisa "Interfaces: técnica, arte e questões ético-políticas no pensamento filosófico" (UNIRIOCNPq). Coordenador do Grupo de Trabalho "Filosofia Política Contemporânea" da ANPOF de 2019 a 2021. Membro do Grupo de Trabalho "Heidegger" (ANPOF). Autor de "Alienações do Mundo: uma interpretação da obra de Hannah Arendt" (São Paulo: Edições Loyola, 2009) e organizador da obra "Política, Direito e Economia no Século XXI" (Rio de Janeiro: Via Verita, 2019), dentre outros trabalhos e publicações em torno das seguintes áreas de pesquisa: História da Filosofia, Filosofia Contemporânea, Filosofia da Tecnologia e Filosofia Política Contemporânea. 